\title{
Studies of Montmorillonite Mechanochemically Decomposed at Different Water Contents
}

\author{
Koichiro Fujimoto, Kiminori Sato \\ Department of Environmental Sciences, Tokyo Gakugei University, Tokyo, Japan \\ Email: koichiro@u-gakugei.ac.jp, sato-k@u-gakugei.ac.jp
}

How to cite this paper: Fujimoto, K. and Sato, K. (2017) Studies of Montmorillonite Mechanochemically Decomposed at Different Water Contents. Geomaterials, 7, 4150. https://doi.org/10.4236/gm.2017.72004

Received: January 18, 2017

Accepted: April 4, 2017

Published: April 7, 2017

Copyright $\odot 2017$ by authors and Scientific Research Publishing Inc. This work is licensed under the Creative Commons Attribution International License (CC BY 4.0).

http://creativecommons.org/licenses/by/4.0/

\begin{abstract}
Clay minerals, as e.g. montmorillonite, abundantly exist in the slip zones such as earthquake faults and landslides. Water contents are an important factor for controlling slip behavior, since montmorillonite contains a considerable amount of water molecules compared with other clay minerals. Here, a series of mechanochemical milling experiments were conducted for montmorillonite at the water contents ranging from $0 \%$ to $800 \%$. Decomposition occurs at the water contents below $25 \%$ and above $600 \%$, which are well correlated with the consistency limits of montmorillonite reported so far, i.e. shrinkage/plastic and liquid limits, respectively. Montmorillonite is found to be effectively decomposed into amorphous materials at the water contents below the shrinkage/plastic limit. In the region of water content between shrinkage/plastic and liquid limits, decomposition cannot be achieved solely by the mechanochemical treatment. At the water contents higher than the liquid limit, decomposition is again started. The present work demonstrates that the degree of decomposition can be of usefulness for speculating how the water molecules behave in the slip zones in nature.
\end{abstract}

\section{Keywords}

Montmorillonite-Water System, Slip Zone, Fault, Milling, Amorphous Material, Consistency Limits

\section{Introduction}

Clay minerals abundantly exist in the slip zones such as earthquake faults and landslides. They are expected to play a significant role in fault lubrication due to the low frictional strength [e.g., [1] [2]]. Smectite group is of particular importance owing to a high capacity of interlayer water expanding the basal spacing under wet conditions [3] [4] [5]. Clay-water system changes its physical state drastically from solid to liquid states via semi-solid and plastic states with in- 
creasing water content. The critical water contents at these transitions are known as consistency limits (Atterberg limits), i.e. shrinkage, plastic, and liquid limits [6].

Amorphous ultrafine particles have been found in a number of clay rich fault planes, which are considered to be the mechanochemically-decomposed products during seismic slip [7] [8] [9] [10]. Hirono et al. [11] recently proposed that the amorphous ultrafine particles remaining at the fault slip planes could be an indicator of the seismic activity. As for the landslide, Okawara et al. [12] predicted that the amorphous materials in the slip zone arise from a paleo-slip. In nature, the slip planes contain a considerable amount of water, largely influencing decomposition behavior as well as the slip properties.

Since 1950's, mechanochemical milling experiments have been conducted for clay minerals, especially for kaolinite [e.g., [13] [14]] and montmorillonite [e.g., [15] [16]], mainly from an industrial point of view. Here, X-ray diffraction (XRD) has been exclusively employed focusing on the crystal structures before and after milling treatments under pressure and temperature. Structural evolution of minerals caused by mechanochemical milling has been thus predicted based on the results of XRD, which is well documented in the literatures [17]. It has not been yet fully understood as to how water contents have an influence on decomposition behavior. Therefore, we performed the mechanochemical milling experiments for montmorillonite as a representative of smectite group at different water contents in this study. Decomposition behavior in the vicinity of consistency limits is highlighted based on the results of X-ray diffraction (XRD), and field emission scanning electron microscopy (FE-SEM), and Fourier transform infrared (FT-IR) spectroscopy.

\section{Materials and Methods}

\subsection{Materials and Sample Preparation}

Starting material is montmorillonite (JCSS-3101; Na-montmorillonite from Tsukinuno, Yamagata Prefecture, NE Japan) provided by Japan Clay Science Society. The representative chemical formula is

$\mathrm{Na}_{0.474}\left(\mathrm{Al}_{1.570} \mathrm{Mg}_{0.322} \mathrm{Fe}_{0.103}\right)\left(\mathrm{Al}_{0.117} \mathrm{Si}_{3.883}\right) \mathrm{O}_{10}(\mathrm{OH})_{2} \cdot \mathrm{nH}_{2} \mathrm{O}$ with a small amount of quartz as impurity. The structural, physical and chemical characteristics are described elsewhere [18].

\subsection{Milling Treatment}

Mechanochemical milling was performed using a planetary ball mill system (Fritsch P6) employing a bowl-ball set made of tungsten carbide. The inner volume of the bowl is $45 \mathrm{ml}$ and the diameter of the milling ball is $5 \mathrm{~mm}$. 180 pieces of milling ball were put into the bowl together with deionized water and the air-dried montmorillonite so that the water/montmorillonite weight ratios were $0 \%, 25 \%, 50 \%, 100 \%, 200 \%, 400 \%, 600 \%$, and $800 \%$. A ball/(powder + water) volume ratio was approximately 1 to 1 . The milling treatments were done with the main disc rotational speed of $400 \mathrm{rpm}$ for 0.5 hour, 3 hours, and 12 hours. 


\subsection{Analytical Methods}

The products after mechanochemical milling were air dried and gently powdered in an agate mortar for XRD experiments and FT-IR spectroscopy. For FE-SEM observations, the powder was suspended in deionized water and a minute quantity of the suspension liquid was dropped on a silicon wafer with micro syringe, and air dried. XRD patterns were obtained using Rigaku RINT1200 (40 kV and $20 \mathrm{~mA}$ with $\mathrm{CuK} \alpha$ radiation) with software JADE6 (Materials Data, Incorporated). Corundum ( $\alpha$-alumina, High Purity Chemicals Co. Ltd.) was added up to $20 \mathrm{wt} \%$ of the run product as an internal standard before XRD analysis. FE-SEM (Hitachi SU-8020) was conducted with the acceleration voltage of $1.5 \mathrm{kV}$ and $2.0 \mathrm{kV}$. FT-IR spectra were obtained using a spectrometer (Nicolet iS 5, Thermo Fisher Scientific) with diamond ATR attachment.

\section{Results}

Figure 1 shows XRD patterns observed for the samples milled at the water contents of $0 \%$ and $25 \%$ for 3 hours, at $50 \%, 400 \%, 600 \%$, and $800 \%$ for 12 hours together with that of starting material. XRD peaks of montmorillonite denoted

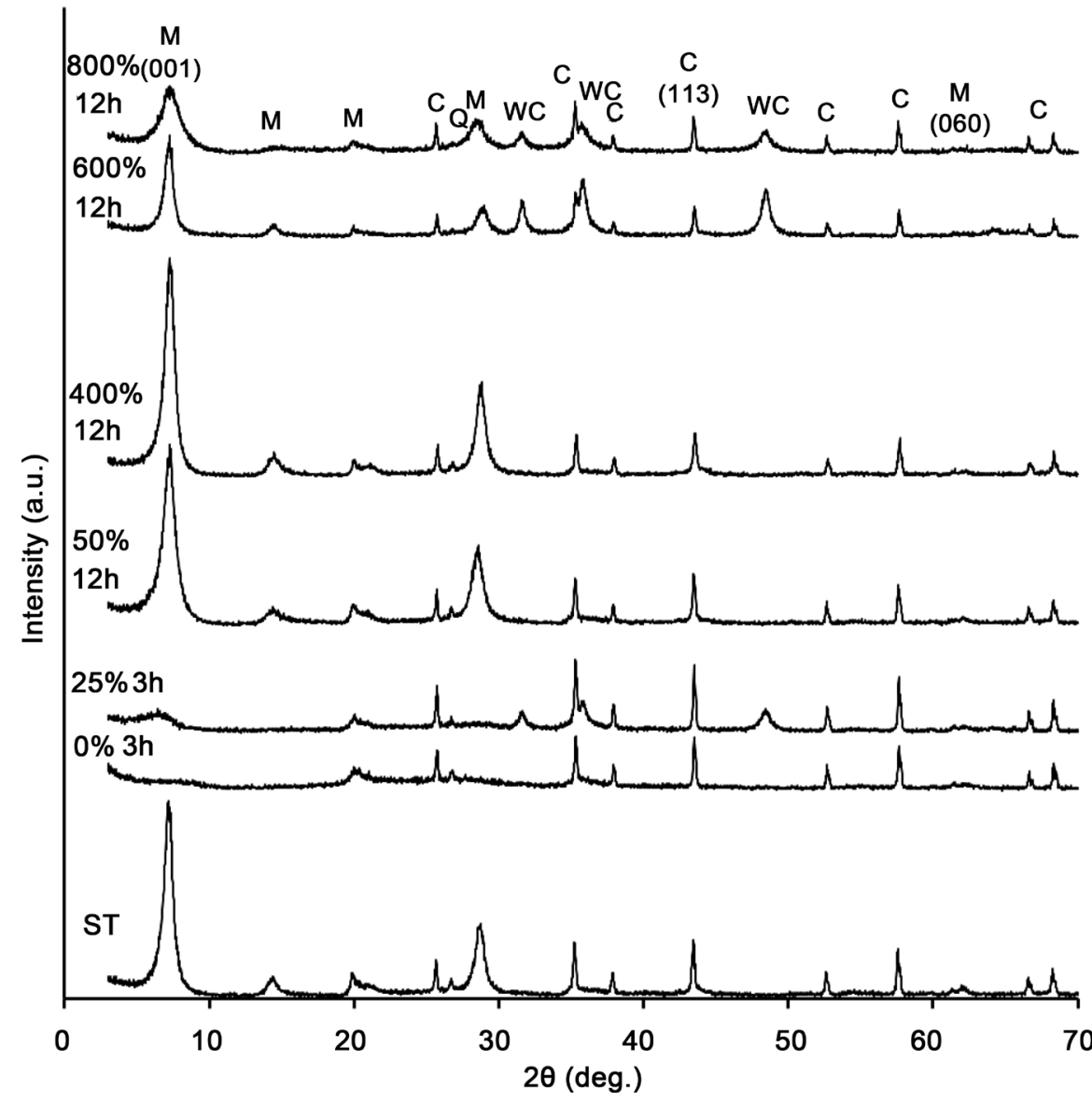

Figure 1. XRD patterns observed for the samples milled at the water contents of $0 \%$ and $25 \%$ for 3 hours, at $50 \%, 400 \%, 600 \%$, and $800 \%$ for 12 hours together with that of starting material (ST). The characters $\mathrm{M}, \mathrm{C}, \mathrm{Q}$, and WC indicate montmorillonite, corundum, quartz and tungsten carbide, respectively. 
as $\mathrm{M}$ disappear for the sample milled under the dry condition (0\%), whereas significant decreases in the peak intensities are seen at 25\%,600\%, and $800 \%$. Furthermore, XRD peaks arising from not only 00n (basal reflections) but also 060 peaks disappear with the increases of background around 25 degrees, which is presumably caused by the formation of silicate rich amorphous materials. On the contrary, the XRD patterns do not show remarkable changes at 50, 100, 200, and $400 \%$. XRD peaks arising from quartz denoted as Q appear regardless of the water contents as well as milling time. The peaks of tungsten carbide at $600 \%$ and $800 \%$ are due to contamination from the milling bowl and balls.

The degree of mechanochemical decomposition can be more quantitatively discussed with the peak intensities of montmorillonite 001 relative to the corundum 113 peaks as shown in Figure 2. The peak intensities rapidly decrease at the water contents of $0 \%$ and $25 \%$, whereas no significant decreases are observed in the range of water content from $50 \%$ to $400 \%$ Again, they begin to decrease at the water contents of $600 \%$ and $800 \%$. The present XRD demonstrate the following sequential process for mechanochemical decomposition for montmorillonite. The crystal structures of montmorillonite are effectively decomposed at the smaller water contents ranging from $0 \%$ and $25 \%$. The decomposition hardly occurs at the water contents of 50\%, 100\%, 200\%, and $400 \%$ even after long milling treatment with 12 hours. The crystal structure of montmorillonite begins to

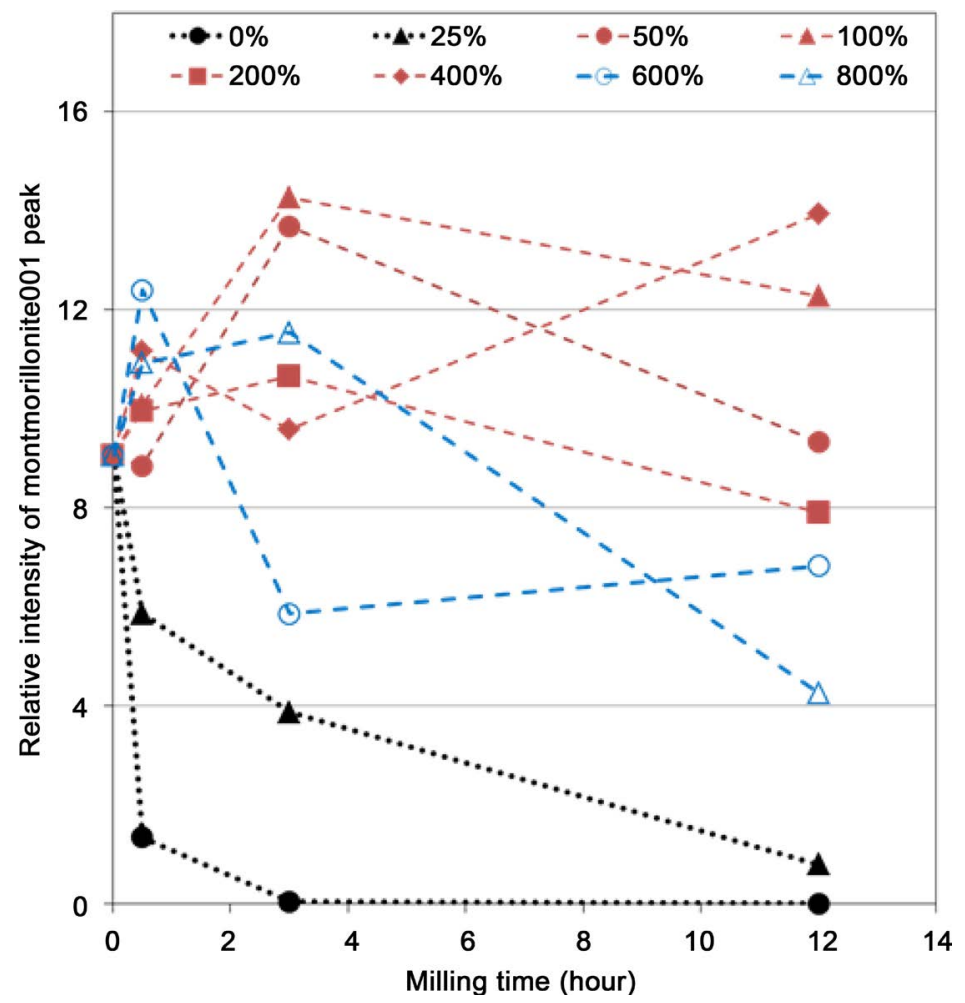

Figure 2. Peak intensities of montmorillonite 001 relative to the corundum 113 peaks as a function of milling time for the samples milled at the water contents of $0 \%$ (black solid circles), 25\% (black solid triangles), at 50\% (red solid circles), 100\% (red solid triangles), $200 \%$ (red solid squares), 400\% (red solid diamonds), 600\% (blue open circles), and $800 \%$ (blue open triangles). 
decompose when the water content is increased up to above $600 \%$. An appearance of inflection point at 3 hours is probably caused by an orientation preference dominated due to strong impact before 3 hours.

Figure 3 shows FE-SEM images of (a) starting material, (b) milled at the water content of $0 \%$ for 3 hours, (c) milled at $25 \%$ for 3 hours, (d) milled at $50 \%$ for 12 hours, (e) milled at $600 \%$ for 12 hours, (f) milled at $800 \%$ for 12 hours. The starting material exhibits the thin flaky shape of about 1 micrometer (see Figure $3(a))$. Upon milled at $0 \%$ for 3 hours, the flaky shape is not preserved forming the agglomeration with the fine particles of less than $100 \mathrm{~nm}$ (Figure $3(\mathrm{~b})$ ). The flaky-shape particles still remain when the sample is milled at $25 \%$ for 3 hours, however, they are partially fragmented indicating tiny globules on the surface of particles (Figure $3(\mathrm{c})$ ). The flaky particles are clearly seen for the sample milled at the water content of $50 \%$ for 12 hours, indicating no significant change is caused by milling (see Figure 3(d)). The SEM images for the samples milled at $100 \%$ for $12 \mathrm{~h}$, at $200 \%$ for $12 \mathrm{~h}$, and at $400 \%$ for $12 \mathrm{~h}$ are similar to that at $50 \%$ for 12 hours, and are thus not shown here. The flaky particles with tiny globules of about a few tens nm again appear upon milling at $600 \%$ and $800 \%$ for 12 hours, which is in consistent with the XRD results.
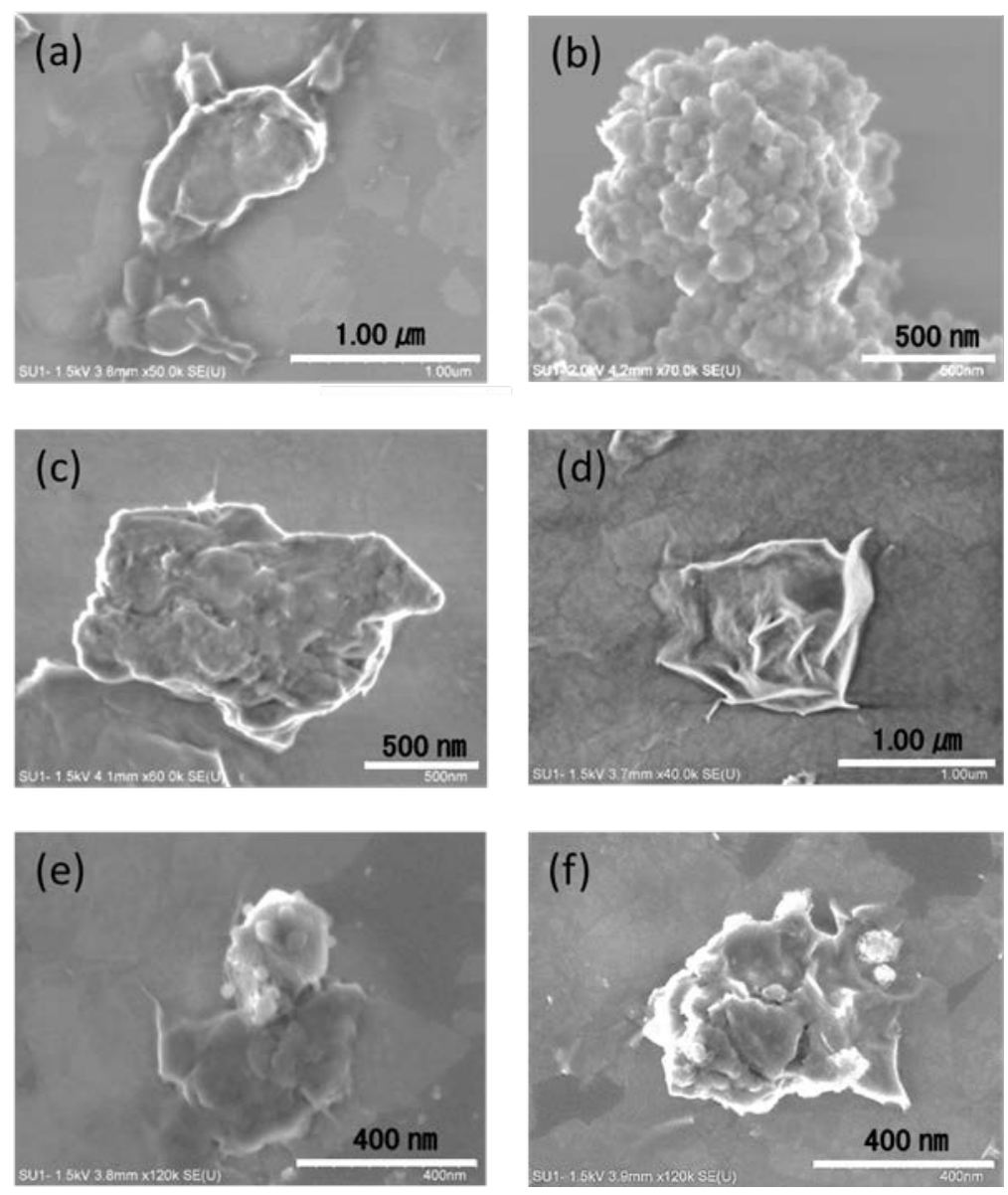

Figure 3. FE-SEM images observed for the samples of (a) starting material, milled at (b) $0 \%$ for 3 hours, (c) $25 \%$ for 3 hours, (d) $50 \%$ for 12 hours, (e) $600 \%$ for 12 hours, and (f) $800 \%$ for 12 hours. 
Figure 4 shows the results of FT-IR spectroscopy, where the peaks of molecular $\mathrm{H}_{2} \mathrm{O}$ and $\mathrm{OH}$ vibration observed for the samples milled at the water contents of $0 \%$ for 3 hours (red solid line), at $25 \%$ for 3 hours (brown solid line), $50 \%$ for 12 hours (green solid line), 600\% for 12 hours (right blue solid line), and $800 \%$ for 12 hours (blue solid line) are presented together with that of starting material (black solid line). The starting material exhibits a sharp $\mathrm{OH}$ vibration peak at the wave number of $\sim 3600 \mathrm{~cm}^{-1}$, the intensity of which is higher than that of broad molecular $\mathrm{H}_{2} \mathrm{O}$ vibration peak at $\sim 3400 \mathrm{~cm}^{-1}$. In contrast to that, the peak intensities of $\mathrm{OH}$ vibration decrease for the samples milled at the water content of $0 \%$ and $25 \%$ for 3 hours, signifying the decomposition of $\mathrm{OH}$ associated region. The peak of $\mathrm{OH}$ vibration recovers for the sample milled at $50 \%$ for 12 hours. The FT-IR data for the samples milled at $100 \%$ for 12 hours, at $200 \%$ for 12 hours, and at $400 \%$ for 12 hours are similar to that at $50 \%$ for 12 hours, and are thus not shown here. The peak intensities of $\mathrm{OH}$ vibration relatively decrease for the samples milled at $600 \%$ and $800 \%$ for 12 hours.

\section{Discussion}

It is known that montmorillonite possess a $2: 1$ layered structure with two-

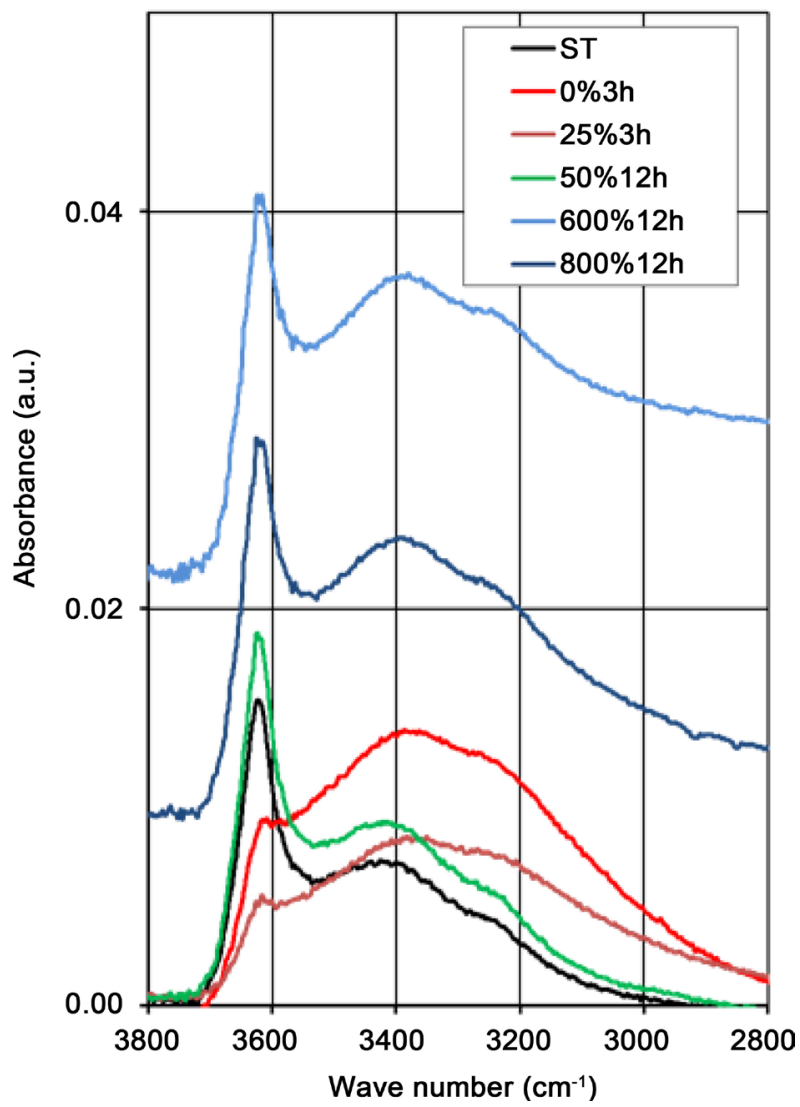

Figure 4. FT-IR spectra of molecular $\mathrm{H}_{2} \mathrm{O}$ and $\mathrm{OH}$ vibrations obtained for the samples milled at the water contents of $0 \%$ for 3 hours (red solid line), at $25 \%$ for 3 hours (brown solid line), 50\% for 12 hours (green solid line), 600\% for 12 hours (light blue solid line), and $800 \%$ for 12 hours (blue solid line) together with that of starting material (black solid line). 
dimensional (2D) nanosheets consisting of tetrahedral sheets and octahedral sheets. Basically, the $\mathrm{O}^{2-}$ and $\mathrm{Si}^{4+}$ are located at the vertices and the central site of the tetrahedron, respectively. The vertices of the octahedron are occupied by $\mathrm{O}^{2-}$ and $\mathrm{OH}^{-}$groups, whereas metallic elements, such as $\mathrm{Al}, \mathrm{Mg}$ and $\mathrm{Fe}$ atoms, are located at the central site. The diminishing of the peaks arising from 060 diffraction and $\mathrm{OH}$ vibration in the XRD and FT-IR data, respectively, thus provide the information that the octahedral sheets are locally decomposed.

As consistently revealed by the XRD experiments, FE-SEM observations, and FT-IR spectroscopy, montmorillonite is effectively decomposed at the low water contents $0 \%$ and $25 \%$. The tendency at the lower water contents below $25 \%$ are in agreement with those observed for saponite, one of smectite group minerals, under the dry condition [19] and for montmorillonite at the water content of $10 \%$ [20]. The crystal structure of montmorillonite maintains without yielding the amorphous materials at the water contents ranging from $50 \%$ to $400 \%$. Decomposition again begins at the higher water contents above $600 \%$. It is thus inferred that the degree of decomposition transits at the water contents at $25 \%$ and $600 \%$. The consistency limits of montmorillonite are accepted as $\sim 10 \%, 54 \sim$ $98 \%$, and $290 \% \sim 710 \%$ for the shrinkage, plastic, and liquid limits, respectively [6]. The transition of decomposition degree at $25 \%$ and $600 \%$ observed in the present work corresponds to the shrinkage/plastic and liquid limits, respectively.

At the water content of $25 \%$, the basal spacing of Na-montmorillonite expands to $18 \AA$, which amounts to three interlayer water [21]. On the one hand, the basal spacing of $12 \AA$ is expected for the starting material, which corresponds to the one interlayer water state. Considering that one interlayer water is roughly estimated to be $9 \mathrm{wt} \%$ [18], three interlayer water amounts to $27 \mathrm{wt} \%$. Under this condition, water molecules exclusively exist in the interlayer spaces, by which montmorillonite could act as a solid material. It is thus expected that impact energy is sufficiently given to montmorillonite in the milling bowl enough to decompose into amorphous materials. This is supported from the analytical results of frictional properties for montmorillonite-based gouge at the hydration states (dry (<4.5 wt\%), 1 layer (6.7 - $8.7 \mathrm{wt} \%), 2$ layer (10.6 - $16.0 \mathrm{wt} \%)$ and 3 layer $(>16.0 \mathrm{wt} \%))$ [22]. At the water contents ranging from $50 \%$ to $400 \%$, montmorillonite-water system as plastic gel paste is formed, in which the impact energy could be dissipated without decomposing montmorillonite. This is evidenced from similar SEM images for the samples milled at 50\% for 12 hours, $100 \%$ for $12 \mathrm{~h}$, at $200 \%$ for $12 \mathrm{~h}$, and at $400 \%$ for $12 \mathrm{~h}$. At the water contents above $600 \%$, the gel state is suppressed yielding an increase in the impact energy. Decomposition is thus again started, which is evidenced from the contamination of tungsten carbide.

As mentioned before, the water contents in the slip zones largely influences the slip properties. The water contents in the natural faults and landslide slip zones are normally considered to be below the liquid limit, since clay minerals flow out under water rich conditions. When the water content is below the shrinkage/plastic limit, montmorillonite can be easily decomposed to be amor- 
phous materials. On the contrary, montmorillonite cannot be decomposed solely by the mechanochemical treatment at the water content above the shrinkage/ plastic limit. The water contents in the slip zones in nature can be thus monitored by the degree of decomposition in montmorillonite.

The slip zones in nature could contain not only montmorillonite but also other minerals such as quartz, feldspars, micas, kaolinite, and etc. These minerals have different physical properties and also influence the slip properties. It is however emphasized here that the slip and shearing properties approach pure montmorillonite at the fraction higher than 30\% [23] [24]. A considerable amount of water can be present in the slip zone at the higher liquid limits, where montmorillonite is decomposed as demonstrated in the present work.

\section{Conclusion}

Clay minerals, as e.g. montmorillonite, abundantly exist in the slip zones such as earthquake faults and landslides. Water contents are an important factor for controlling slip behavior, since montmorillonite contains a considerable amount of water molecules compared with other clay minerals. Here, mechanochemical milling experiments were systematically conducted for montmorillonite in the wide water content region from $0 \%$ to $800 \%$. The decomposition behavior was discussed based on the results of XRD experiments, FE-SEM observations, and FT-IR spectroscopy. Mechanochemical decomposition occurs at the water contents below $25 \%$ and above $600 \%$. It was found that the degree of decomposition transits at the water contents of $25 \%$ and $600 \%$. The critical water contents of $25 \%$ and $600 \%$ observed here are well correlated to the shrinkage/plastic and liquid limits, respectively. At the water contents below the shrinkage/plastic limit, montmorillonite is effectively decomposed into amorphous materials. In the region of water content between shrinkage/plastic and liquid limits, montmorillonite is hardly decomposed exclusively by the mechanochemical treatment. Decomposition is again started at the water contents higher than the liquid limit. The present work demonstrates that the degree of decomposition can be of usefulness for speculating how the water molecules behave in the slip zones in nature and could extend to the field study.

\section{Acknowledgements}

This work was partially supported by Grant-in-Aid for Scientific Research (C) (24540485 and 15K05308). Thanks are also due to Ms. Rei Endo for her help in the experiments.

\section{References}

[1] Di Toro, G., Han, R., Hirose, T., De Paola, N., Nielsen, S., Mizoguchi, K., Ferri, F., Cocco, M. and Shimamoto, T. (2011) Fault Lubrication during Earthquakes. Nature, 471, 494-499.

http://www.nature.com/nature/journal/v471/n7339/abs/nature09838.html https://doi.org/10.1038/nature09838

[2] Ikari, M.J., Marone, C. and Saffer, D.M. (2011) On the Relation between Fault 
Strength and Frictional Stability. Geology, 39, 83-86.

http://geology.gsapubs.org/content/39/1/83.short https://doi.org/10.1130/G31416.1

[3] Moor, D. and Lockner, D. (2007) Friction of the Smectite Clay Montmorillonite: A Review and Interpretation of Data. In: Dixon, T.H. and Moore, J.C., Eds., The Seismogenic Zone of Subduction Thrust Faults, Columbia University Press, New York, 318-345. https://doi.org/10.7312/dixo13866-011

[4] Ikari, M.J., Saffer, D.M. and Marone, C. (2009) Frictional and Hydrologic Properties of Clay-Rich Fault Gouge. Journal of Geophysical Research, 114, B05409.

http://onlinelibrary.wiley.com/doi/10.1029/2008JB006089/full https://doi.org/10.1029/2008JB006089

[5] Kameda, J., Shimizu, M., Ujiie, K., Hirose, T., Ikari, M., Mori, J., Oohashi, K. and Kimura, G. ( 2015) Pelagic Smectite as an Important Factor in Tsunamigenic Slip along the Japan Trench. Geology, 43, 155-158.

http://geology.gsapubs.org/content/43/2/155.short https://doi.org/10.1130/G35948.1

[6] Lambe, T.W. and Whitman, R.V. (1969) Soil Mechanics. John Wiley \& Sons, New York.

[7] Ozawa, K. and Takizawa, S. (2007) Amorphous Material Formed by the Mechanochemical Effect in Natural Pseudotachylyte of Crushing Origin: A Case Study of the Iida-Matsukawa Fault, Nagano Prefecture, Central Japan. Journal of Structural Geology, 29, 1855-1869.

[8] Ma, K.-F., Tanaka, H., Song, S.-R., Wang, C.-Y., Hung, J.-H., Tsai, Y.-B., Mori, J., Song, Y.-F., Yeh, E.-C., Soh, W., Sone, H., Kuo, L.-W. and Wu, H.-Y. (2006) Slip Zone and Energetics of a Large Earthquake from the Taiwan Chelungpu-Fault Drilling Project. Nature, 444, 473-476.

http://www.nature.com/nature/journal/v444/n7118/abs/nature05253.html https://doi.org/10.1038/nature05253

[9] Hirono, T., Kameda, J., Kanda, H., Tanikawa, W. and Ishikawa, T. (2014) Mineral Assemblage Anomalies in the Slip Zone of the 1999 Taiwan. Chi-Chi Earthquake: Ultrafine Particles Preserved Only in the Latest Slip Zone. Geophysical Research Letters, 41, 3052-3059.

http://onlinelibrary.wiley.com/doi/10.1002/2014GL059805/full https://doi.org/10.1002/2014GL059805

[10] Lin, A. (2008) Fossil Earthquakes: The Formation and Preservation of Pseudotachylytes. Springer-Verlag, Berlin Heidelberg. http://link.springer.com/book/10.1007\%2F978-3-540-74236-4

[11] Hirono, T., Asayama, S., Kaneki, S. and Ito, A. (2016) Preservation of Amorphous Ultrafine Material: A Proposed Proxy for Slip during Recent Earthquakes on Active Faults. Scientific Reports, 6, 36536.

https://www.ncbi.nlm.nih.gov/pmc/articles/PMC5101524/

https://doi.org/10.1038/srep36536

[12] Okawara, M., Yoneda, T., Mitachi, T. and Tada, M. (1996) Mineralogical/Chemical Evaluation of Shear Zone Clay for Paleo-Slip Surface Determination-A Case Study in the Myoukurasawa Paleo-Landslide Area, Iwate Prefecture. Japan Society of Engineering Geology, 37, 2-13.

[13] Hamzaoui, R., Muslim, F., Guessasma, S., Bennabi, A. and Guillin J. (2015) Structural and Thermal Behavior of Proclay Kaolinite Using High Energy Ball Milling Process. Powder Technology, 271, 228-237.

[14] Sugiyama, K., Filio, J. M., Saito, F. and Waseda, Y. (1994) Structural Change of Kao- 
linite and Pyrophyllite Induced by Dry Grinding. Mineralogical Journal, 17, 28-41.

[15] Bekri-Abbes, I. and Srasra, E. (2016) Effect of Mechanochemical Treatment on Structure and Electrical Properties of Montmorillonite. Journal of Alloys and Compounds, 671, 34e42.

[16] Dellisanti, F., Minguzzi, V. and Valdrè, G. (2006) Thermal and Structural Properties of Ca-Rich Montmorillonite Mechanically Deformed by Compaction and Shear. Applied Clay Science, 31, 282-289.

http://www.sciencedirect.com/science/article/pii/S0169131705001250

[17] Juhasz, A.Z. and Opoczky, L. (1990) Mechanical Activation of Minerals by Grinding Pulverizing and Morphology of Particles. Halsted Press, New York.

[18] Miyawaki, R., Sano, T., Ohashi, F., Suzuki, M., Kogure, T., Okumura, T., Kameda, J., Umezome T., Sato, T., Chino, D., Hiroyama, K., Yamada, H., Tamura, K., Morimoto, K., Uehara, S. and Hatta, T. (2010) Some Reference Data for the JCSS Clay Specimens. The Clay Science Society of Japan, 48, 158-198.

http://www.cssj2.org/old_home/cssj_ref.pdf

[19] Numata, K., Sato, K., Fujimoto, K. and Fujiwara, K. (2014) Study of Decomposition Mechanism for Inorganic-Layered Saponite Nanoparticle. Radioisotopes, 63, 389 397. https://www.jstage.jst.go.jp/article/radioisotopes/63/8/63_389/_article

[20] Xia, M., Yinshan, J., Zhao, L., Li, F., Xue, B., Sun, M., Liu, D. and Zhang, X. (2010) Wet Grinding of Montmorillonite and Its Effect on the Properties of Mesoporous Montmorillonite. Colloids and Surfaces A: Physicochemical and Engineering Aspects, 356, 1-9.

[21] Kawamura, K., Ichikawa, Y., Nakano, M., Kitayama, K. and Kawamura, H. (1999) Swelling Properties of Smectite Up to $90^{\circ} \mathrm{C}$ in Situ X-Ray Diffraction Experiments and Molecular Dynamic Simulations. Engineering Geology, 54, 75-79. http://www.sciencedirect.com/science/article/pii/S0013795299000630

[22] Ikari, M.J., Saffer, D.M. and Marone, C. (2007) Effect of Hydration State on the Frictional Properties of Montmorillonite-Based Fault Gouge. Journal of Geophysical Research, 112, B06423.

http://onlinelibrary.wiley.com/doi/10.1029/2006JB004748/full https://doi.org/10.1029/2006JB004748

[23] Yamasaki, T., Mayumi, T. and Yoshita, E. (2000) Ring Shear Characteristics of High Purity Clay Minerals-Correlation with Natural Slip Surface Clay. Journal of the Japan Landslide Society, 37, 30-39. https://doi.org/10.3313/jls1964.37.2_30

[24] Takahashi, M., Mizoguchi, K., Kitamura, K. and Masuda, K. (2007) Effects of Clay Content on the Frictional Strength and Fluid Transport Property of Faults. Journal of Geophysical Research, 112, B08206.

http://onlinelibrary.wiley.com/doi/10.1029/2006JB004678/full

https://doi.org/10.1029/2006JB004678 
Submit or recommend next manuscript to SCIRP and we will provide best service for you:

Accepting pre-submission inquiries through Email, Facebook, LinkedIn, Twitter, etc. A wide selection of journals (inclusive of 9 subjects, more than 200 journals)

Providing 24-hour high-quality service

User-friendly online submission system

Fair and swift peer-review system

Efficient typesetting and proofreading procedure

Display of the result of downloads and visits, as well as the number of cited articles Maximum dissemination of your research work

Submit your manuscript at: http://papersubmission.scirp.org/

Or contact gm@scirp.org 